\title{
Differential gene expression is tied to photochemical efficiency reduction in virally infected Emiliania huxleyi
}

\author{
Ilana C. Gilg ${ }^{1}$, Stephen D. Archer ${ }^{1}$, Sheri A. Floge ${ }^{1,2}$, David M. Fields ${ }^{1}$, \\ Alex I. Vermont ${ }^{1}$, Anna H. Leavitt ${ }^{1}$, William H. Wilson ${ }^{1,3}$, \\ Joaquín Martínez Martínez ${ }^{1, *}$ \\ ${ }^{1}$ Bigelow Laboratory for Ocean Sciences, 60 Bigelow Dr., East Boothbay, ME 04544, USA \\ ${ }^{2}$ Present address: Department of Microbiology, Ohio State University, Riffe Building, 496 W 12th Ave., Columbus, \\ OH 43210, USA \\ ${ }^{3}$ Present address: Sir Alister Hardy Foundation for Ocean Science (SAHFOS), The Laboratory, Citadel Hill, \\ Plymouth PL1 2PB, UK
}

\begin{abstract}
Photophysiological changes in phytoplankton have important implications for the structure and function of planktonic communities and ocean biogeochemistry. Viruses have been shown to decrease photochemical efficiency $\left(F_{\mathrm{v}} / F_{\mathrm{m}}\right)$ of Emiliania huxleyi late in infection, although the precise timing and mechanism of this reduction remain largely unexplored. We coupled high-resolution temporal measurements of photosystem II (PSII) efficiency during coccolithovirus EhV-86 infection with expression of host psbA (D1), PSII assembly and repair genes (ctpA, ftsH, and HCF136), and antioxidant genes (ascorbate peroxidase [apx] and superoxide dismutase [sod2]) using digital PCR. $F_{\mathrm{v}} / F_{\mathrm{m}}$ declined significantly in infected cultures from $1.25 \mathrm{~h}$ postinoculation (p.i.), while non-photochemical quenching (NPQ), measured as the normalized SternVolmer parameter, significantly increased from $4.0 \mathrm{~h}$ p.i. These changes were preceded by significant decreases in expression of ctpA and ftsH (25 min p.i.) and of HCF136 (1 h p.i.). Significant down-regulation of sod2 homologs and apx was observed later, starting at 1 to $3 \mathrm{~h}$ p.i. Our data suggest that virus-induced photophysiological changes may begin with a reduction in PSII repair and assembly, followed by a reduction in antioxidants that may result in an accumulation of damaged PSII complexes. Elevated NPQ during infection may help dissipate excess energy resulting from damage to PSII. This study illustrated that viral infection leads to a cascade of significant changes in the expression of genes assessed during this study, which may lead to the observed reduction in photosynthetic performance.
\end{abstract}

KEY WORDS: Coccolithovirus - EhV-86 - Digital PCR $\cdot$ Photochemical efficiency $\cdot$ PSII repair

\section{INTRODUCTION}

Emiliania huxleyi (Prymnesiophyceae) is a cosmopolitan marine coccolithophore that can form massive blooms and significantly influence marine primary productivity (Paasche 2001) and microbial biogeochemical cycling (Burkill et al. 2002). Coccolithoviruses have been shown to facilitate the demise

*Corresponding author: jmartinez@bigelow.org of E. huxleyi blooms (Bratbak et al. 1993, Wilson et al. 2002b) and restore microbial ecosystem diversity using a kill-the-winner mechanism (Castberg et al. 2001). Viruses may profoundly alter the photophysiology of marine phytoplankton during infection, with direct impacts on carbon fixation rates (Suttle et al. 1990) and intracellular carbon metabolism (Thompson et al. 2011). However, the effects of viral infec-

() The authors 2016. Open Access under Creative Commons by Attribution Licence. Use, distribution and reproduction are unrestricted. Authors and original publication must be credited.

Publisher: Inter-Research · www.int-res.com 
tions in phytoplankton differ among specific hostvirus systems; therefore, it is important to investigate the exact impact viruses have on the photophysiology of individual host groups. In some systems, viral production is contingent on photosynthetic performance (Suttle \& Chan 1993, Clokie et al. 2006).

Cyanophages harbor homologs of critical photosynthesis-related and core photosystem II (PSII) genes to preserve the efficiency of light reactions during infection (Mann et al. 2003, Dammeyer et al. 2008). Some viruses, like Micromonas pusilla virus SP1, may even enhance photochemical efficiency at specific stages of infection (Brown et al. 2007). However, many viral infections result in a decline in photochemical efficiency (Van Etten et al. 1983, Juneau et al. 2003). Previous studies of the E. huxleyi-coccolithovirus system have revealed a clear decline in PSII maximum photochemical efficiency during late stages of viral infection (Evans et al. 2006, Bidle et al. 2007, Kimmance et al. 2014), although the underlying mechanisms remained unclear. One mechanistic explanation for viral-mediated reduction in photochemical efficiency may be associated with the repair of PSII. Under light intensities that exceed the excitation energy that can be used for charge separation, several reactive intermediates may be formed which preferentially and irreversibly damage the D1 protein at the core of the PSII complex (Kyle et al. 1984). Although D1 damage may occur at all light intensities, when the rate of D1 damage exceeds the rate of repair, the resulting loss of function is termed photoinhibition (Adir et al. 2003). The term photoinhibition is often extended to include decreased rates of photosynthesis resulting from excitation energy dissipation to limit D1 damage. To maintain steady-state levels of functional PSII, the damaged D1 protein must be rapidly and efficiently turned over in a multi-step damage-repair cycle (Nishiyama et al. 2011). For example, half of the D1 pool is turned over every $20 \mathrm{~min}$ in irradiancestressed Dunaliella salina compared to a $7 \mathrm{~h}$ half-life under a normal light regime (Kim et al. 1993a). Irreversible damage to D1 is thought to initiate the repair cycle by triggering the partial disassembly of the PSII complex, where the damaged D1 may be proteolytically removed and replaced in a highly coordinated fashion, while the other subunits are reused (Komenda et al. 2012).

In current embryophytic (= higher) plant models, the PSII repair cycle is thought to be comprised of 6 main steps (Nath et al. 2013), which we briefly describe here, highlighting the function of the genes targeted during our study. First, core proteins on a damaged PSII supercomplex undergo reversible phosphorylation, which initiates the repair cycle, and the damaged core complex monomerizes. Second, the damaged PSII core complex monomer is separated from functional PSII units, and the core complex proteins are subsequently dephosphorylated. The core complex then splits into CP47-RC and CP43 subunits. The third and fourth steps occur in tandem. Damaged D1 is proteolytically degraded while a newly synthesized precursor D1 (pD1), the product of the plastid gene $p s b A$, is integrated de novo into the partially assembled complex via chloroplast translation machinery. Degradation and removal of damaged D1 is primarily conducted by metalloprotease FtsH (Wagner et al. 2012), although other proteases such as DegP2 also play a minor role in this process (Nixon et al. 2005). Another important protein at this stage in the repair cycle is PSII assembly/repair factor HCF136 (known as YCF48 in Arabidopsis thaliana), which acts to stabilize the pD1 protein in the thylakoid membrane during synthesis while simultaneously stabilizing the reaction core complex (Komenda et al. 2008). At the fifth step, pD1 is fully matured to D1 by carboxy-terminal processing protease (CtpA), which removes the pD1 carboxy-terminal (C-terminal) extension exposed on the lumenal side of the complex (Shestakov et al. 1994, Satoh \& Yamamoto 2007). This step is critical to PSII repair because the extending C-terminal polypeptides prevent binding of the extrinsic oxygen-evolving complex to the PSII core complex and generate nonfunctional PSII (Roose \& Pakrasi 2004). Once D1 is matured, the final steps in the repair cycle are the reassembly of the monomeric PSII complex with the reestablishment of the extrinsic oxygen-evolving complex and reintegration of $\mathrm{CP} 43$, followed by final reassembly of the functional PSII dimeric supercomplex. HCF136 and CtpA are also necessary factors for efficient de novo assembly of PSII and perform the same functions in a newly assembled PSII core complex as they do in the repair cycle (Roose \& Pakrasi 2004, Komenda et al. 2008). FtsH, by contrast, is only involved in the repair cycle (Wagner et al. 2012).

The formation of reactive oxygen species (ROS), including singlet oxygen $\left({ }^{1} \mathrm{O}_{2}\right)$, superoxide anion $\left(\mathrm{O}_{2}{ }^{--}\right)$, hydrogen peroxide $\left(\mathrm{H}_{2} \mathrm{O}_{2}\right)$, and hydroxyl radi$\mathrm{Cal}$, is an unavoidable consequence of electron transport processes during oxygenic photosynthesis (Latifi et al. 2009, Pospíšil 2009). ROS may cause oxidative damage to many cellular components (e.g. proteins, lipids, nucleic acids), although in PSII, the primary site of ROS damage is thought to be the D1 subunit (Adir et al. 2003). Superoxide dismutase (SOD) antioxidants are believed to be the first line of 
defense against oxidative stress (Mittler 2002) because they convert $\mathrm{O}_{2}{ }^{\circ-}$, produced on the reducing side of photosystem I (PSI), to $\mathrm{H}_{2} \mathrm{O}_{2}$, which can be further reduced by several processes including, but not limited to, the water-water cycle (Asada 2006). In this cycle, ascorbate peroxidase (APX) in the chloroplast reduces $\mathrm{H}_{2} \mathrm{O}_{2}$ to water using ascorbate. APX also plays a key role in the ascorbate-glutathione cycle, which provides a mechanism for reducing $\mathrm{H}_{2} \mathrm{O}_{2}$ in nearly all cellular compartments, including the chloroplast (Mittler 2002). Additionally, nonphotochemical quenching (NPQ) enhances the dissipation of excess excitation energy in the form of heat, protecting PSII by reducing the production of ${ }^{1} \mathrm{O}_{2}$ and decreasing the energy transfer to the reaction centers. There are 3 components to NPQ, a $\mathrm{pH}$ - or energy-dependent component (qE), a component involving uncoupling of light-harvesting complexes and the reaction centers (state transitions), and a third component that comprises photoinhibition and photodamage (qI). The largest and most immediate component is $\mathrm{qE}$, which involves the reversible de-epoxidation of xanthophyll pigments (oxygenated carotenoids) in the light-harvesting antenna. The xanthophyll cycle occurs in 2 forms, the violaxanthin cycle and the diadinoxanthin cycle. In the violaxanthin cycle, which occurs in most chlorophytes, phaeophytes, and plants, excess light causes the de-epoxidation of violaxanthin, initially to antheraxanthin and then to zeaxanthin. E. huxleyi, along with many other algal protists, possesses the additional diadinoxanthin cycle, where excess light conditions cause the de-epoxidation of diadinoxanthin to diatoxanthin (Stransky \& Hager 1970). Under certain conditions, these organisms can utilize both the violaxanthin cycle and the diadinoxanthin cycle (Lohr \& Wilhelm 1999).

Intracellular and extracellular ROS increase in $E$. huxleyi cultures during late stages of infection with the lytic virus EhV-86 (Evans et al. 2006) and with a mixed viral assemblage in mesocosms (Vardi et al. 2012), although the mechanism(s) driving this production and/or accumulation is unclear. ROS production may be induced by virus-encoded glycosphingolipids to trigger a cascade of programmed cell death (Bidle \& Vardi 2011). ROS may also increase as a result of compromised photochemistry (Evans et al. 2006). While many studies have investigated changes occurring during later stages of infection (close to cell lysis, rapid decline of the host population, and an associated large increase in extracellular virions), to our knowledge, there has been no detailed investigation into photophysiological changes that may occur during early infection (from the virus entry to the release of virions via budding, prior to substantial measurable cell lysis and accumulation of extracellular virions). In the present study, we coupled highresolution temporal measurements of PSII efficiency and NPQ with expression of host psbA, key PSII repair/assembly genes (fts $\mathrm{H}, \mathrm{HCF} 136$, and ctpA), and antioxidant genes (superoxide dismutase [sod2] and ascorbate peroxidase $[a p x]$ ) to investigate whether transcriptional changes underlie the reduction in photochemical efficiency observed in infected $E$. huxleyi.

\section{MATERIALS AND METHODS}

\section{Experimental setup and sample collection}

Non-axenic Emiliania huxleyi strain CCMP374 was long-term maintained in mid-exponential growth phase (specific growth rates $0.3-0.45 \mathrm{~d}^{-1}$ ) by periodical transfers in $\mathrm{f} / 2$-Si media (Guillard \& Ryther 1962) at $16^{\circ} \mathrm{C}$ under a $14 \mathrm{~h}$ light: $10 \mathrm{~h}$ dark cycle. Incubators were outfitted with cool white fluorescent bulbs, and cultures received a photon flux density of $100 \mu \mathrm{mol}$ photons $\mathrm{m}^{-2} \mathrm{~s}^{-1}$. For this study, a $20 \mathrm{l}$ volume culture was grown under those same conditions. When the culture reached mid-exponential growth phase $(6 \times$ $10^{5}$ cells ml ${ }^{-1}$ ), the culture was divided equally among 6 polycarbonate carboys. At $30 \mathrm{~min}$ prior to virus inoculation with coccolithovirus EhV-86, samples from each carboy were collected for baseline measurements. Virus-free E. huxleyi CCMP374 cultures displayed near-synchronous division that started approximately $1 \mathrm{~h}$ before the lights came on and lasted about $4 \mathrm{~h}$. EhV-86 virus addition was timed to coincide with the end of the cytokinesis to minimize the effect of division on the physiological measurements. Next, $300 \mathrm{ml}$ of fresh virus lysate $(0.45 \mu \mathrm{m}$ filtered $)$ was added to 3 carboys (infected cultures) to achieve a 33:1 total virus:host cell ratio. This ratio, within the range commonly encountered in nature, was intended to achieve a high initial proportion of infected cells (Wilson et al. 2002a, Martínez Martínez et al. 2007, Highfield et al. 2014). To control for the effects of added nutrients and dissolved organic compounds in the virus lysate, $300 \mathrm{ml}$ of virus-free $(0.1 \mu \mathrm{m}$ filtered) lysate was added to the 3 remaining carboys (control cultures). Time $0(t 0)$ samples were collected from the carboys at this time. Under constant mixing, $100 \mathrm{ml}$ aliquots from each carboy were then transferred via sterile tubing into $125 \mathrm{ml}$ polycarbonate flasks (Corning), and the flasks were returned to the incubator. At 
each time point, 3 biological replicate control flasks and 3 biological replicate infected flasks were removed from the incubator, sampled, and discarded. Samples were collected in the following order: photosynthetic efficiency, RNA, total host enumeration and percent infection, and virus enumeration. Sample collection took place approximately every $30 \mathrm{~min}$ for the first $5 \mathrm{~h}$ post inoculation (p.i.) with the virus and then approximately every hour thereafter up to $12 \mathrm{~h}$. The final samples were collected at 19, 22, and $24 \mathrm{~h}$, respectively.

\section{Photophysiology}

Four milliliters from each replicate flask were transferred to a sterile $15 \mathrm{ml}$ black polypropylene tube and incubated in the dark at $16^{\circ} \mathrm{C}$ for $10 \mathrm{~min}$ (derived empirically to accommodate the high temporal sampling resolution). Samples were analyzed on a FastOcean-FastAct ${ }^{\mathrm{TM}}$ Fast Rate Repetition fluorometer (Chelsea Technologies Group). Filtered $(\mathrm{GF} / \mathrm{F})$, cell-free controls were analyzed as blanks. Maximum photochemical efficiency of dark-adapted cultures $\left(F_{\mathrm{v}} / F_{\mathrm{m}}\right)$ is presented in this study. $F_{\mathrm{v}} / F_{\mathrm{m}}$ data were obtained from single turnover (ST) acquisitions using a light-emitting diode saturating light source of $0.6 \times 10^{22}$ photons $\mathrm{m}^{-2} \mathrm{~s}^{-1}$, centered at $450 \mathrm{~nm}$.

The normalized Stern-Volmer parameter (NSV) is used to quantify NPQ. NSV is the ratio of the total non-photochemical dissipation in the light-adapted state to the photochemical rate constant. NSV is defined as NSV $=\left(F_{\mathrm{m}}{ }^{\prime} / F_{\mathrm{v}}{ }^{\prime}\right)-1$ (e.g. McKew et al. 2013a). NSV was determined at $99 \mu \mathrm{mol}$ photons $\mathrm{m}^{-2} \mathrm{~s}^{-1}$ photosynthetically active radiation (PAR), comparable to the PAR irradiance to which the cells were exposed during the incubations (approximately $100 \mu \mathrm{mol}$ photons $\mathrm{m}^{-2} \mathrm{~s}^{-1}$ ). This was done to obtain an indication of the physiological state of the cells during the incubations rather than to determine a capacity for NPQ when exposed to higher irradiance, as may be more appropriate in a natural setting with variable light levels.

\section{Infection dynamics}

One milliliter samples from each flask were collected for virus enumeration, fixed in $0.5 \%$ glutaraldehyde, stored at $4^{\circ} \mathrm{C}$ for 15 to $30 \mathrm{~min}$, and then flash frozen in liquid $\mathrm{N}_{2}$ and stored at $-80^{\circ} \mathrm{C}$ until analysis. Viruses were enumerated using a BD FACScan flow cytometer and SYBR-Green I stain as described elsewhere (Brussaard et al. 2010). Host cell abundance and percentage of infected cells were quantified in real time without sample preservation. Cells were stained using the orange fluorescent lipid stain N-(3-triethylammoniumpropyl)-4-(4-(dibutylamino) styryl) pyridinium dibromide (FM 1-43, Life Technologies). Visibly infected E. huxleyi cells were differentiated from uninfected cells on a BD FACScan flow cytometer based on changes in lipid composition or abundance as indicated by changes in the orange fluorescence signal (Martínez Martínez et al. 2011). Total cell abundance was determined by flow cytometry (FCM), triggering on chlorophyll red fluorescence. FCM data were analyzed with BD Cell Quest $^{\mathrm{TM}}$ Pro, v. 5.2.1. Growth rates $(K)$ were calculated by the following equation (Levasseur et al. 1993):

$$
K=\frac{\ln \left(\frac{N 2}{N 1}\right)}{t 2-t 1}
$$

where $N 1$ and $N 2$ equal cell counts at time $1(t 1)$ and time $2(t 2)$, respectively.

\section{Selection of genes involved in PSII repair and antioxidant function}

In light of their important role in the maturation, activation, and repair of D1, fts $H, \mathrm{HCF} 136$, and $\operatorname{ctp} A$ genes were chosen for differential expression analysis in addition to $p s b A(\mathrm{pD} 1)$ (Table 1). To investigate the effect of virus infection on an early antioxidant response, 2 sod 2 paralogs and apx were also selected for monitoring. The precise site of activity of SOD2 (MnSOD) in E. huxleyi is unknown, and localization of various SOD isoforms vary greatly among photosynthetic organisms (Kitayama et al. 1999, Li et al. 2002, Pilon et al. 2011); MnSOD is localized in the chloroplasts in the marine diatom Thalassiosira pseudonana (Wolfe-Simon et al. 2006) as a low-iron adaptation. Like T. pseudonana, the E. huxleyi pangenome lacks FeSOD isoforms (Read et al. 2013), possessing instead 2 putative MnSOD paralogs based on the presence of 2 conserved residues at the active site cavity (Abreu \& Cabelli 2010) as well as 2 putative $\mathrm{Cu} / \mathrm{ZnSOD}$ paralogs. However, we did not detect either of the $\mathrm{Cu} / \mathrm{ZnSOD}$ (SOD1) paralogs in pooled cDNA from E. huxleyi CCMP374 by PCR, nor could we find them in a transcriptome dataset of the same strain (MMETSP1006-MMETSP1009; http:// data.imicrobe.us/project/view/104). In addition, a recent E. huxleyi proteomic study only detected SOD2A (364889) out of the 4 annotated isoforms (McKew et al. 2013b), suggesting that MnSOD 
(SOD2) dominates in this organism. For these reasons, we only investigated SOD2 expression in this study. Multiple (4) ascorbate peroxidase paralogs were also identified in the E. huxleyi pan-genome (Read et al. 2013), although 2 are not found in strain 374 . Of the remaining 2 core paralogs, only 434150 was detected in CDNA samples by PCR, and it was also the only paralog present in the MMETSP transcriptome, providing our justification to select it for expression analysis.

\section{RNA purification}

Fifteen milliliters from each flask were transferred to a sterile polypropylene conical tube, spun at $16^{\circ} \mathrm{C}$ at $10000 \times g$ for $10 \mathrm{~min}$, and decanted. The cell pellet was resuspended in $500 \mu \mathrm{l}$ lysis buffer (Absolutely RNA Microprep Kit, Agilent) containing 3.5 $\mu \mathrm{l} \beta$-mercaptoethanol per sample and flash frozen in liquid $\mathrm{N}_{2}$. Gene expression data were plotted according to the time when lysis buffer was added to the cell pellet, i.e. 10 to 15 min after sample collection from culture flasks. Samples were stored at $-80^{\circ} \mathrm{C}$ until ready for extraction and purification.

Total RNA was extracted and purified using the Absolutely RNA Microprep Kit with a TRIzol@ Reagent (Life Technologies) extraction step. Briefly, samples were thawed on ice and then transferred to RNase-free microcentrifuge tubes preloaded with approximately $50 \mu \mathrm{l}$ glass beads and $500 \mu \mathrm{l}$ TRIzol@ Reagent (1:1 v/v TRIzol:lysis buffer). Samples were bead beaten on a Vortex Genie for $5 \mathrm{~min}$. Next, $120 \mu \mathrm{l}$ of 1-bromo-3-chloropropane was added to each lysate, and the samples were mixed 15 times by inversion and then incubated at room temperature for $5 \mathrm{~min}$. Samples were centrifuged at $10000 \times g$ for $15 \mathrm{~min}$ at $4^{\circ} \mathrm{C}$, and the aqueous phase was transferred to a fresh tube. Half-volumes $(500 \mu l)$ of cold ethanol were added to each tube, and the tubes were inverted to mix. The ethanol/lysate mixture was transferred to an Absolutely RNA Microprep spin column and purified according to the manufacturer's instructions. We performed the optional in-column DNase digestion after column binding but prior to purification at $37^{\circ} \mathrm{C}$ for $30 \mathrm{~min}$, as per the manufacturer's instructions. Samples were eluted in $45 \mu \mathrm{l}$ RNA elution buffer; $5 \mu \mathrm{l}$ of RNA stock were immediately aliquoted into a separate tube for quantification and quality control. The remaining $40 \mu \mathrm{l}$ of purified RNA were stored at $-80^{\circ} \mathrm{C}$. RNA quality and quantity were measured using an Experion ${ }^{\mathrm{TM}}$ Automated Electrophoresis System (Bio-Rad).

\section{Reverse transcription}

RNA (10-25 $\mu$ l) from each sample was reverse transcribed (RT) using the VILO cDNA Synthesis Kit according to the manufacturer's protocol (Life Technologies). We employed the optional 90 min incubation at $42^{\circ} \mathrm{C}$ to enhance cDNA yield and ensure complete conversion. RT reactions were diluted in nucleasefree water to obtain approximate DNA concentrations of $5 \mathrm{ng} \mathrm{hl}^{-1}$. This was done to minimize the amount of random hexamers in subsequent quantitative PCR (qPCR) reactions and to obtain optimal transcript copy numbers for digital PCR (dPCR). Parallel samples were also subject to the same conditions but without the reverse transcriptase to account for the presence of any genomic DNA (gDNA).

\section{Gene expression of infected and control cultures}

qPCR was optimized for the RainDrop dPCR system (RainDance Technologies). Assay design, dPCR optimization, and analysis details may be found in the Supplement at www.int-res.com/articles/suppl/ m555p013_supp.pdf. qPCR reactions were multiplexed in $25 \mu \mathrm{l}$ total volumes containing $1 \mathrm{X}$ TaqMan® Genotyping Master Mix (Life Technologies), $1 \mathrm{X}$ droplet stabilizer, and $2 \mu \mathrm{l}$ diluted experimental cDNA template. Expression was quantified for each target gene (Table 1) in multiplex reactions. Multiplex A included assays HCF136-TET, ctpA-TET, and sod2A-FAM. Multiplex B included assays sod2B-TET and $\mathrm{ftsH}$-FAM. Multiplex $\mathrm{C}$ included the apx-FAM assay, among others. Each multiplex reaction included additional FAM or TET assays not part of this study. qPCR reactions contained $900 \mathrm{nM}$ of each primer set and $200 \mathrm{nM}$ probe, except for $c t p A$-TET and sod2A-FAM, which contained $450 \mathrm{nM}$ primers and $100 \mathrm{nM}$ probe. PCR reaction volumes were parsed into 5 million droplets per sample and then amplified in a C1000 Touch deep-well thermal cycler (BioRad) with the following thermal protocol: $95^{\circ} \mathrm{C}$ for $10 \mathrm{~min} ; 95^{\circ} \mathrm{C}$ for $15 \mathrm{~s}$ and then $60^{\circ} \mathrm{C}$ for $60 \mathrm{~s}$, with a ramping rate of $0.5^{\circ} \mathrm{C} \mathrm{s}^{-1}$ for 55 cycles; and final inactivation at $98^{\circ} \mathrm{C}$ for $10 \mathrm{~min}$. The droplets were enumerated on the RainDrop Sense (RainDance Technologies), and the data were analyzed in RainDropAnalyst (v. 14.0.0.0) and displayed as 2-dimensional scatter plots. Positive reactions for each assay were seen as discrete clusters within the plots (Fig. S1 in the Supplement). PCR-positive populations were gated and analyzed as recommended by RainDance Technologies and normalized to $10 \mathrm{ng}$ of 
template. Quantification of gDNA contamination for the $\mathrm{ftsH}$, apx, and sod2B assays was performed using $2 \mu \mathrm{l}$ of no-RT RNA template under the same reaction conditions described earlier in this paragraph (see Supplement for details). gDNA in the $\mathrm{ftsH}$ assay accounted for $1.6 \%$ of total targets for this assay on average and never exceeded $17 \%$, while the presence of gDNA in the sod2B assay accounted for an average of $8.5 \%$ of total targets and never exceeded $35 \%$. gDNA in the apx assay averaged $0.5 \%$ and never exceeded $11 \%$.

psbA expression was quantified using standard qPCR. It was unsuitable to include this assay in multiplex dPCR reactions because the expression of this gene was several orders of magnitude higher than the others we investigated. qPCR reactions for $p s b A$ were run in $25 \mu \mathrm{l}$ total volumes containing $1 \mathrm{X}$ AccuStart $^{\mathrm{TM}}$ Genotyping ToughMix® without ROX (Quanta), $900 \mathrm{nM}$ psbA total primers, $200 \mathrm{nM}$ psbAFAM probe (Table 1), and $2 \mu \mathrm{l}$ diluted experimental cDNA template. Samples were run in a CFX96 Touch $^{\text {TM }}$ Real-Time PCR Detection System (Bio-Rad) with the following thermal protocol: $95^{\circ} \mathrm{C}$ for $10 \mathrm{~min}$ followed by $95^{\circ} \mathrm{C}$ for $15 \mathrm{~s}$ and then $60^{\circ} \mathrm{C}$ for $60 \mathrm{~s}$, with a fluorescence reading after each cycle. Standard curves were generated from an 8-fold dilution series of purified linear PCR product eluted in water and were used to determine copy number, which was then normalized to $10 \mathrm{ng}$ template. The presence of gDNA in the psbA assay accounted for an average of $0.06 \%$ of total targets for this assay and never exceeded $0.38 \%$.

Table 1. Emiliania huxleyi probe and primer sequences designed for this study. Assays highlighted in light and dark grey were co-amplified in respective multiplex reactions. Protein IDs are from the E. huxleyi pan-genome (http://genome.jgi.doe.gov/ Emihu1/Emihu1.home.html) unless noted otherwise. Transcript sequences were extracted from the Gordon and Betty Moore Foundation Marine Microbial Eukaryote Transcriptome Sequencing Project datasets MMETSP1006-1009 (http://data. imicrobe.us/project/view/104). cDNA-specific assays contain primers designed to span exon:exon junctions. PSII: photosystem II

\begin{tabular}{|c|c|c|c|c|}
\hline $\begin{array}{l}\text { Target } \\
\text { gene }\end{array}$ & $\begin{array}{l}\text { Putative protein } \\
\text { description }\end{array}$ & $\begin{array}{l}\text { Protein } \\
\text { ID(s) }\end{array}$ & CCMP 374 transcript IDs & Forward primer \\
\hline $\operatorname{apx}$ & Ascorbate peroxidase & 434150 & $\begin{array}{l}\text { MMETSP1008-20130614|1315_1 } \\
\text { MMETSP1007-20130614|6208_1 }\end{array}$ & ATCGTGGCGGATGTCAAAG \\
\hline $\operatorname{ctp} A$ & $\begin{array}{l}\text { Carboxy-terminal } \\
\text { processing protease }\end{array}$ & 315400 & $\begin{array}{l}\text { MMETSP1006-20130614|1566_1 } \\
\text { MMETSP1007-20130614|1315_1 } \\
\text { MMETSP1008-20130614|38163_1 }\end{array}$ & GCAATACCGGAGGCTACTTTAC \\
\hline $\mathrm{ftsH}$ & $\begin{array}{l}\text { ATP-dependent metallo- } \\
\text { protease FtsH }\end{array}$ & 427625 & $\begin{array}{l}\text { MMETSP1006-20130614|1520_1 } \\
\text { MMETSP1007-20130614|6408_1 } \\
\text { MMETSP1008-20130614|663_1 } \\
\text { MMETSP1009-20130614|844_1 }\end{array}$ & ACСТCAACATCATCGCCAAG \\
\hline HCF136 & $\begin{array}{l}\text { PSII stability/ assembly } \\
\text { factor HCF136-138 }\end{array}$ & $\begin{array}{l}461307 \\
425813 \\
253334\end{array}$ & $\begin{array}{l}\text { MMETSP1006-20130614|13358_1 } \\
\text { MMETSP1007-20130614|2015_1 } \\
\text { MMETSP1008-20130614|13085_1 } \\
\text { MMETSP1009-20130614|39011_1 }\end{array}$ & СТTCСТCAAGGACTCCAACAC \\
\hline$p s b A$ & PSII protein D1 & AEI29481 & $\begin{array}{l}\text { MMETSP1008-20130614|34448_1 } \\
\text { MMETSP1006-20130614|1278_1 }\end{array}$ & CGGTTGTCTAATGTTCCCTACTC \\
\hline $\operatorname{sod} 2 B$ & $\begin{array}{l}\text { Superoxide dismutase } \\
\text { (MnSOD) }\end{array}$ & 354736 & $\begin{array}{l}\text { MMETSP1006-20130614|3917_1 } \\
\text { MMETSP1007-20130614|3944_1 } \\
\text { MMETSP1008-20130614|1144_1 } \\
\text { MMETSP1009-20130614|4198_1 }\end{array}$ & GCGGAGGCTTTGTCAATCA \\
\hline $\operatorname{sod} 2 A$ & $\begin{array}{l}\text { Superoxide dismutase } \\
\text { (MnSOD) }\end{array}$ & 364889 & $\begin{array}{l}\text { MMETSP1006-20130614|7915_1 } \\
\text { MMETSP1007-20130614|768_1 } \\
\text { MMETSP1008-20130614|15482_1 } \\
\text { MMETSP1009-20130614|7316_1 }\end{array}$ & CCATGGCCAAGGCGTTT \\
\hline
\end{tabular}

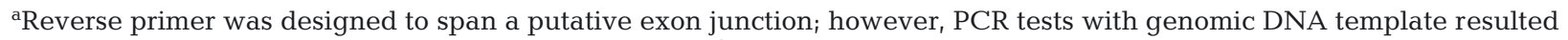
in amplification, so a genomic subtraction was applied; ${ }^{b}$ From GenBank 


\section{RESULTS}

\section{Infection dynamics}

Emiliania huxleyi subpopulations within the infected cultures exhibited changes in lipid staining compared to control cultures, with a shift toward relatively high and low orange fluorescence signal from $2 \mathrm{~h}$ p.i. onward, detectable by FCM (Fig. 1A,C). By $4 \mathrm{~h}$ p.i., approximately $50 \%$ of $E$. huxleyi cells in the infected cultures had changed their relative orange fluorescence signal. That percentage continued to increase beyond $80 \%$ from $9 \mathrm{~h}$ p.i. to a maximum of $88 \%$ by $24 \mathrm{~h}$ p.i. Cells with altered orange fluorescence signature, likely due to membrane blebbing (Mackinder et al. 2009), were previously shown to be infected (Martínez Martínez et al. 2011). The total number of cells in the infected cultures began to slowly decrease after $5 \mathrm{~h}$ p.i. However, a substantial increase in virus production was not observed in the infected cultures until after $12 \mathrm{~h}$ p.i. (Fig. 1B). In con- trast, the control cultures continued to grow at a specific rate of approximately $0.3 \mathrm{~d}^{-1}$ (Fig. 1A). Viruses were not detected in those cultures, which received an addition of $0.1 \mu \mathrm{m}$ filtered EhV-86 lysate at $t_{0}$. The high orange fluorescence population was also observed in the control cultures, yet it remained a small (mean 3.6\%) and relatively constant subpopulation over the course of the experiment, never exceeding $6 \%$ of the total control population (Fig. S3 in the Supplement). A low orange fluorescence subpopulation was never observed in control cultures.

\section{Photophysiology}

To achieve the high-resolution temporal measurements required use of a shorter dark acclimation period (10 min) than is typical (15-30 min). To confirm that this period was sufficient, on 2 occasions, at -0.5 and $8.5 \mathrm{~h}$ p.i., the effect of extending this period was tested. $F_{\mathrm{m}}$ decreased slightly by 1 to $2 \%$ and 0 to

\begin{tabular}{llll} 
Reverse primer & Probe & $\begin{array}{c}\text { Probe } \\
\text { label }\end{array}$ & $\begin{array}{l}\text { cDNA-specific } \\
\text { assay }\end{array}$ \\
\hline TTGAGGCTGCCGTTTGAA & CGATTCTCATCCGGCTATCGTGGC (Sense) & FAM & $\begin{array}{l}\text { No; gene contains } \\
\text { no introns }\end{array}$ \\
GTGTCCATGCCGTCGTC & ACGTTCGTGACCGACAACCGTC (Sense) & TET & Yes (R primer) \\
CGTAGTCGACCTGCTCGTA & CTCGTTGAGCAGGTTTGCGAGC (AntiSense) & FAM & No $^{\text {a }}$ \\
CGTTGGAGAAGGACTTGATCTT & TACAGGTTGGTTGGCAAGTCGTCC (AntiSense) & TET & Yes (F primer) \\
CAACTGGCTCACGGATACC & TACTGGAGGTGCTGCGATGAAAGC (AntiSense) & FAM & No; gene contains \\
no introns
\end{tabular}



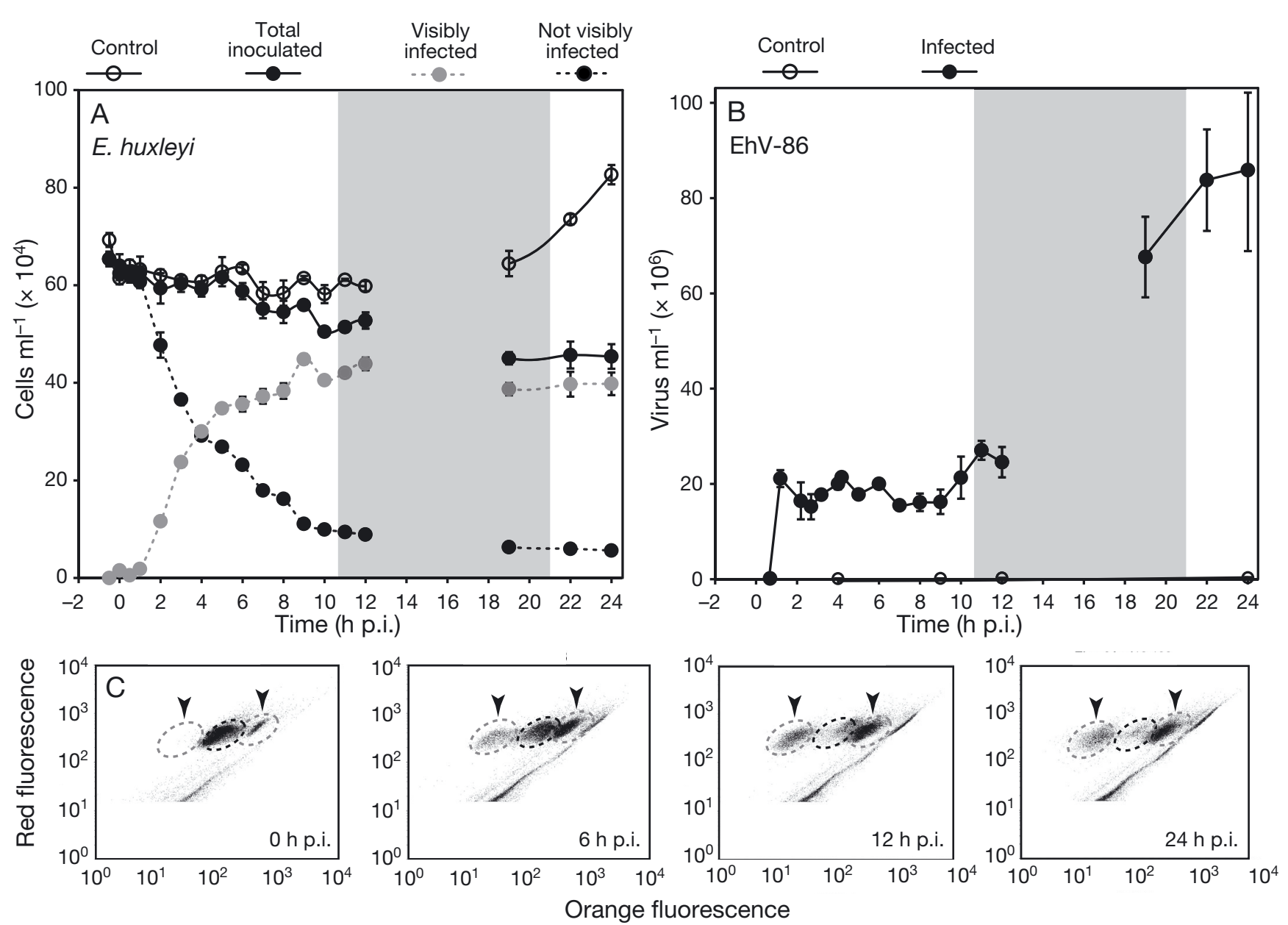

Fig. 1. Infection dynamics. (A) Emiliania huxleyi CCMP374 cell abundance in virus-free control and in cultures inoculated with EhV-86 coccolithoviruses. The latter was further categorized into visibly infected and not visibly infected subpopulations, shown with dashed lines. Error bars indicate $\pm 1 \mathrm{SD}(\mathrm{n}=3)$. Shaded region reflects the dark period of the $14 \mathrm{~h}$ light:10 h dark cycle. (B) EhV-86 coccolithovirus abundance in control and virus-inoculated cultures. Error bars indicate $\pm 1 \mathrm{SD}$ ( $\mathrm{n}=3$ ). (C) Flow cytometry dotplots of virus-inoculated E. huxleyi at selected time points, with orange fluorescence (lipid stain FM 1-43) plotted against red (chlorophyll) fluorescence. As the infection progressed, changes in lipid staining are revealed by the appearance of subpopulations with relatively higher and lower orange fluorescence signal (grey dashed gates marked with arrows). Black dashed gate corresponds to the subpopulation of the cells not visibly infected. Dotplot at $0 \mathrm{~h}$ post inoculation (p.i.) is also representative of the control cultures throughout the experiment (see Fig. S3 in the Supplement at www.int-res.com/ articles/suppl/m555p013_supp.pdf)

$1 \%$, respectively, relative to the value at $10 \mathrm{~min}$ when the dark acclimation was extended to $\sim 20 \mathrm{~min}$, with no obvious difference in response between the infected and control cultures at $8.5 \mathrm{~h}$ p.i. The lack of an increase in $F_{\mathrm{m}}$ following extended dark acclimation indicates that the 10 min duration prior to the ST acquisition measurements was sufficient to allow relaxation of NPQ and PSII reaction centers to fully open.

Values of $F_{\mathrm{v}} / F_{\mathrm{m}}$ showed a small but statistically significant (2-tailed Welch's $t$-test, $\mathrm{p}<0.001)$ decline in the infected cultures starting at $1.25 \mathrm{~h}$ p.i. (mean reduction $3 \pm 0.07 \% \mathrm{SD}$ ) (Fig. $2 \mathrm{~A}$ ). The maximum photochemical efficiency continued to decline more markedly as time progressed: $7.4 \%$ by $6.5 \mathrm{~h}$ p.i., $15.2 \%$ by $12.4 \mathrm{~h}$ p.i., $29.7 \%$ by $19.5 \mathrm{~h}$ p.i., and $48.2 \%$ by $23.5 \mathrm{~h}$ p.i. (Fig. 2A).

Significantly higher NSV occurred in infected cultures at $4 \mathrm{~h}$ p.i., when a $23 \%$ increase over control values was observed (2-tailed Welch's $t$-test, $\mathrm{p}<0.01$ ) (Fig. 2B). NSV continued to rise in the infected cultures for the remainder of the sampling period. As the irradiance level was constant and similar between treatments, this indicates a greater requirement to dissipate excess energy from PSII in the infected cells. 

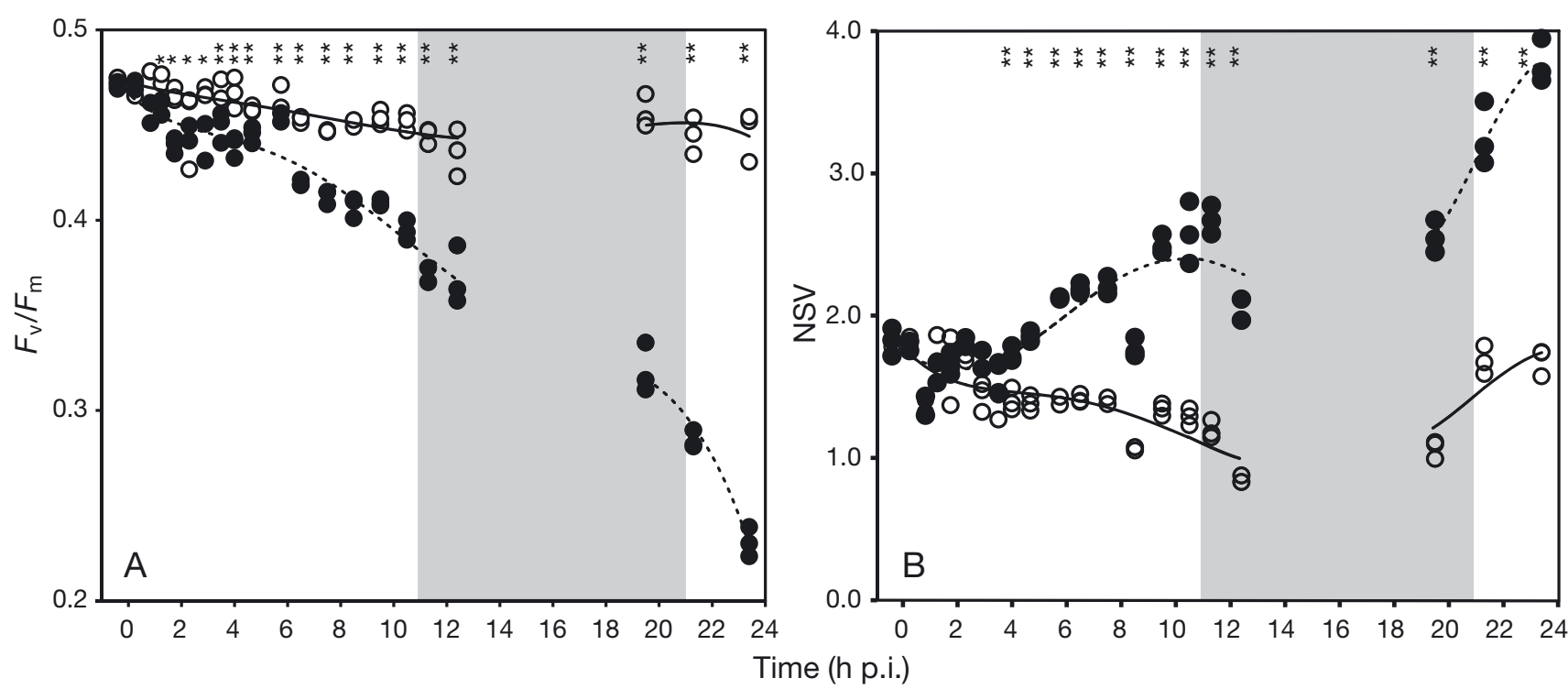

Fig. 2. Photophysiological responses of Emiliania huxleyi to EhV-86 infection over the first 24 h post inoculation (p.i.). Virusfree control cultures (O) and infected cultures $(\bullet)$ are shown with individual replicates plotted. Shaded areas represent the dark period of the $14 \mathrm{~h}$ light: $10 \mathrm{~h}$ dark cycle. The data were fitted with $5^{\text {th }}$ degree polynomial regressions. Significant and highly significant differences between infected and control cultures are indicated (Welch's $t$-test ${ }_{i}{ }^{*} \mathrm{p}<0.05,{ }^{* *} \mathrm{p}<0.001$, respectively). (A) Photochemical efficiency of dark-adapted cells during infection, measured as $F_{\mathrm{v}} / F_{\mathrm{m}}$. (B) Normalized Stern-Volmer parameter (NSV) at $99 \mu \mathrm{mol}$ photons $\mathrm{m}^{-2} \mathrm{~s}^{-1}$ photosynthetically active radiation during infection

\section{Gene expression}

There was no significant difference in transcript copy number of $p s b A(\mathrm{pD} 1)$ in infected cultures relative to the controls for the first $19 \mathrm{~h} . p s b A$ transcript copies were only significantly lower after $23.5 \mathrm{~h}$ into the infection (2-tailed Welch's $t$-test, $\mathrm{p}<0.05$ ) (Fig. 3A). In contrast, expression of the putative PSII repair and assembly genes ftsH (metalloprotease $\mathrm{FtsH}$ ) and ctpA (C-terminal processing protease) in infected cultures was significantly lower within 25 min of inoculation (54 and $34 \%$ lower mean expression, respectively; 2-tailed Welch's $t$-test, $\mathrm{p}<$ 0.05) (Fig. 3B,D). Expression of putative HCF136 (PSII stability/assembly factor HCF136-138) genes was also lower at this time, although the observed difference in transcript copy number was not statistically significant until approximately $1 \mathrm{~h}$ p.i. ( $52 \%$ mean expression reduction; $\mathrm{p}<0.05$ ) (Fig. 3C). HCF136, ftsH, and ctpA transcript copy numbers remained low throughout the course of infection, and the difference in gene expression between infected and control cultures was significant at most but not all time points. Nonetheless, expression of all 3 genes in infected cultures was significantly repressed from 8.5 h p.i. (Fig. 3).

Expression of antioxidant sod2 paralogs in infected cultures was also lower relative to controls, although the first significant differences in expression were observed later than in PSII assembly/repair transcript levels. sod $2 A$ and sod2B displayed similar expression profiles, although the expression levels of $\operatorname{sod} 2 A$ were roughly 5 times those of $\operatorname{sod} 2 B$ (Fig. 4). Significantly lower sod2A expression in infected cultures was first observed at $2 \mathrm{~h}$ p.i. (Fig. $4 \mathrm{~A}_{i} 62 \%$ lower; 2 tailed Welch's $t$-test, $\mathrm{p}<0.05$ ) and at $3 \mathrm{~h}$ p.i. in $\operatorname{sod} 2 B$ (Fig. 4B; $47 \%$ lower; 2-tailed Welch's $t$-test, $\mathrm{p}<0.05$ ). Expression of sod $2 B$ was $26 \%$ higher in the infected cultures than the control at $1.5 \mathrm{~h}$ p.i. (Fig. $4 \mathrm{~B}_{;} \mathrm{p}=$ 0.03), although it was less than the control at sampling points thereafter. Like the PSII assembly/repair genes, expression of both sod2 paralogs was significantly lower in infected cultures from $8.5 \mathrm{~h}$ onwards $(\mathrm{p}<0.05)$. Significant repressed expression in apx was observed even earlier in infected cultures, at $1 \mathrm{~h}$ p.i. (Fig. $4 C_{i} p<0.05$ ), and remained lower than controls thereafter.

From 0 to $4 \mathrm{~h}$ p.i., the mean fold changes in expression of PSII repair, antioxidant genes (except apx), and $p s b A$ demonstrated only a slight decline, ranging from -1.12 to -2.36 (Fig. S2 in the Supplement). By comparison, from 4.6 to $12.25 \mathrm{~h}$ p.i., mean fold changes decreased to $-3.97,-4.10,-5.22,-8.65$, -10.96, and -15.52 for ftsH, ctpA, HCF136, sod2A, $\operatorname{sod} 2 B$, and $a p x$, respectively. These increasing rates of down-regulation preceded increased $(\geq 7.4 \%$ from $6.5 \mathrm{~h}$ p.i.) reduction in the photochemical efficiency and statistically significant increases in NPQ in the 

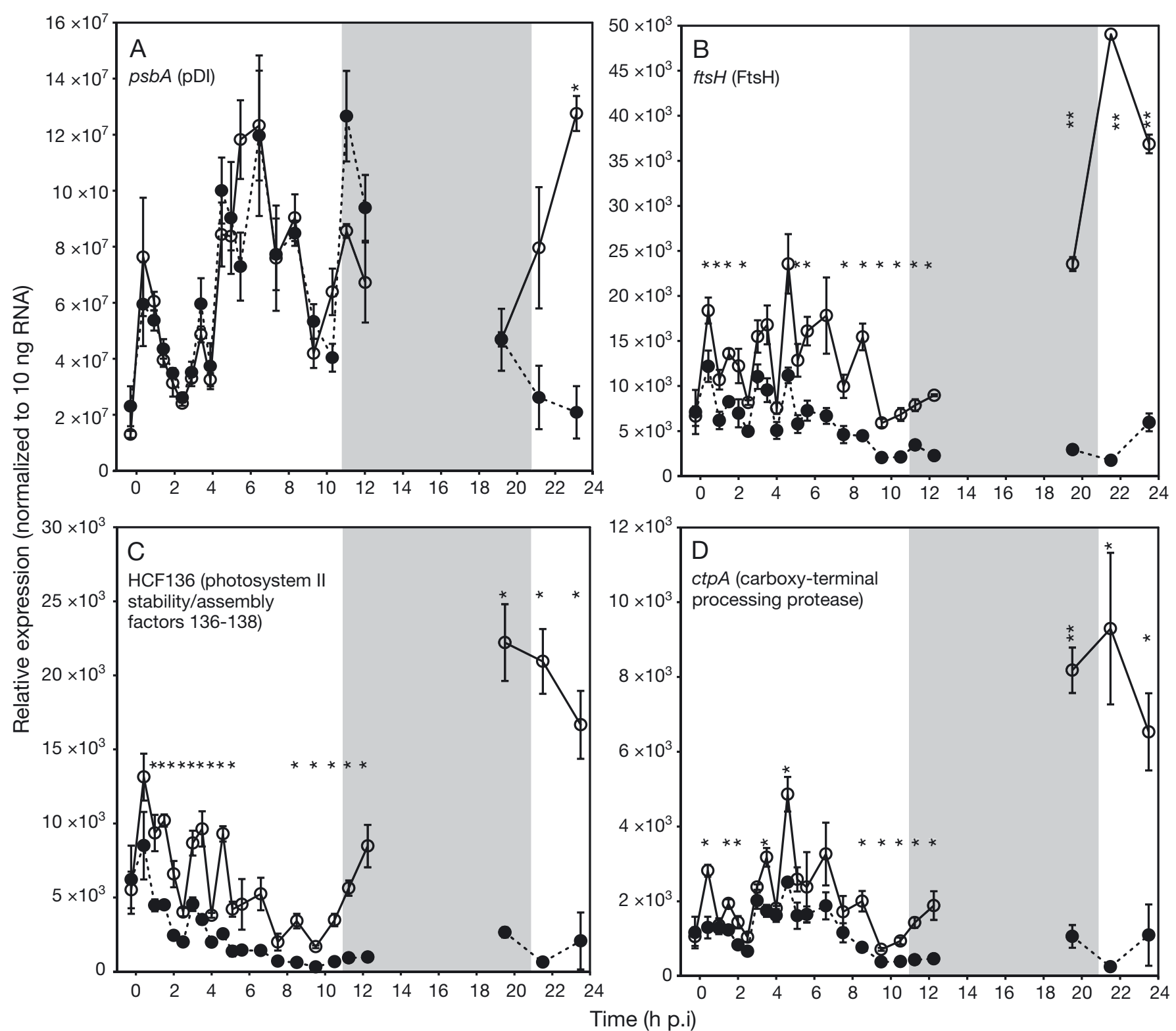

Fig. 3. Differential expression of photosystem II repair and assembly genes (A) psbA, (B) ftsH, (C) HCF136-38, and (D) ctpA as quantified by digital PCR. Virus-free control cultures $(O)$ and infected cultures ( $)$ are shown \pm SE. Shaded regions represent the dark period of the $14 \mathrm{~h}$ light:10 h dark cycle. Significant and highly significant differences between infected and control cultures are indicated (Welch's $t$-test ${ }^{*} \mathrm{p}<0.05,{ }^{* *} \mathrm{p}<0.001$, respectively). p.i.: post inoculation

infected cultures ( $\geq 310 \%$ from 5.75 h p.i.) (Fig. 2). This was in stark contrast to $p s b A$ expression, which appeared largely unchanged until the very end of the experiment (Fig. S2 in the Supplement).

\section{DISCUSSION}

While previous studies have shown virus-induced reductions in $F_{\mathrm{v}} / F_{\mathrm{m}}$ after $24 \mathrm{~h}$ or more (Evans et al. 2006, Bidle et al. 2007, Llewellyn et al. 2007, Vardi et al. 2009), our results suggest that reductions in $F_{\mathrm{v}} / F_{\mathrm{m}}$ begin earlier than previously reported and that early reductions or repression of gene expression for PSII repair and antioxidant scavenging may be a contributing factor. This study allowed a glimpse into the timing of some of the molecular mechanisms that may underlie such reductions. The application of highly sensitive dPCR enabled detection of a small but significant lower copy number of transcripts key to photosynthesis during the early stages of EhV-86 infection of Emiliania huxleyi CCMP374. While 

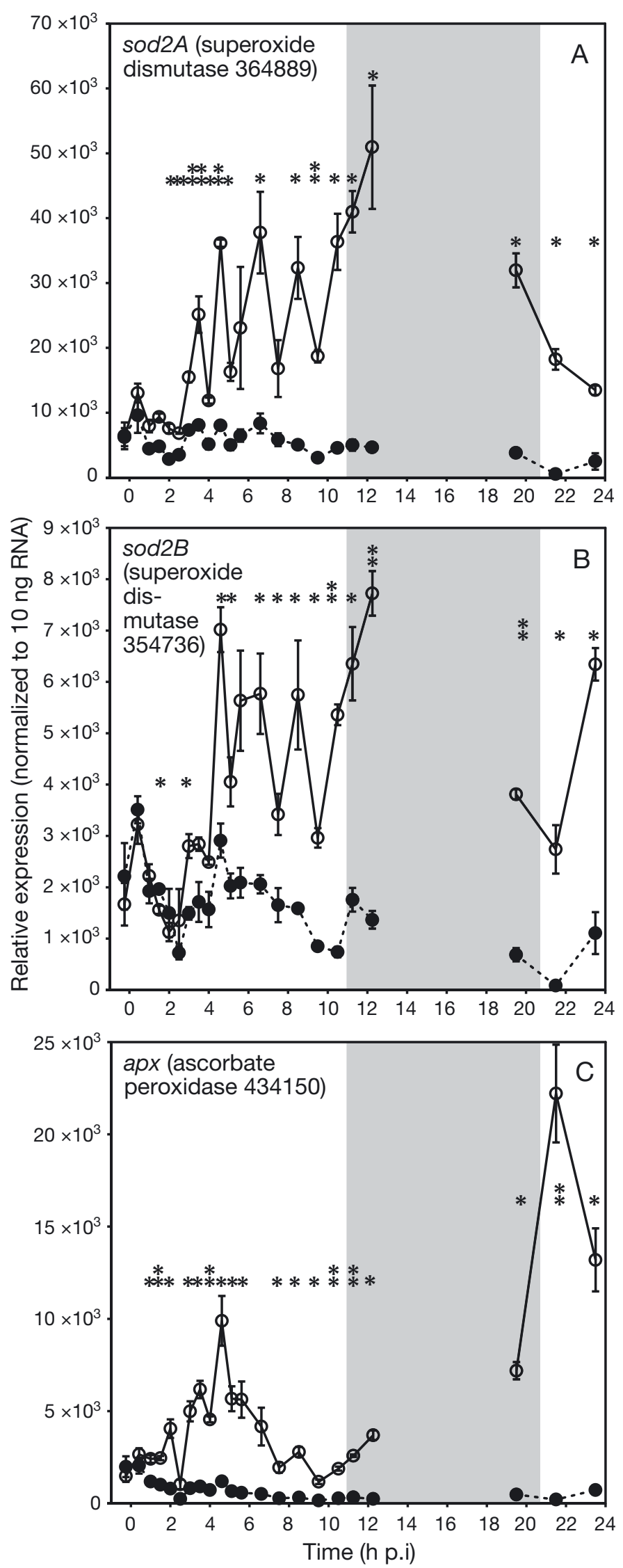

Fig. 4. Differential expression of (A) $\operatorname{sod} 2 A$, (B) $\operatorname{sod} 2 B$, and (C) apx genes up to $24 \mathrm{~h}$ post inoculation (p.i.) as quantified by digital PCR. Virus-free control cultures (O) and infected cultures $(\bullet)$ are shown \pm SE. Shaded region represents the dark period of the $14 \mathrm{~h}$ light:10 h dark cycle. Significant and highly significant differences between infected and control cultures are indicated (Welch's $t$-test; ${ }^{*} \mathrm{p}<0.05,{ }^{* *} \mathrm{p}<0.001$, respectively)

restricted in the total number of genes examined, our dPCR data provided new insights complementary to those obtained by whole transcriptome and whole metabolomics approaches (Kegel et al. 2010, Rosenwasser et al. 2014).

The rapid repression we observed in expression of the PSII repair genes targeted in this study from approximately $5 \mathrm{~h}$ p.i. onward is consistent with whole transcriptome-based analyses (i.e. Kegel et al. 2010) and may lead to an accumulation of non-functional PSII complexes in the thylakoids, thereby reducing $F_{\mathrm{v}} / F_{\mathrm{m}}$. An effective PSII repair cycle is important not only to help maintain or regain photochemical efficiency but also to avoid cytotoxicity by ROS production in partial PSII complexes. Dramatic increases in $\mathrm{H}_{2} \mathrm{O}_{2}$ and $\mathrm{O}_{2}{ }^{--}$concentrations have been observed in the chloroplasts of Arabidopsis mutants lacking metalloproteases FtsH2 or FtsH5 under non-photoinhibitory photon flux densities (Kato et al. 2009). Those results clearly demonstrated that enhanced ROS production can be a direct consequence of an impaired PSII repair cycle with implications for virusinduced suppression of $\mathrm{ftsH}$ expression in our study. Other research conducted on HCF136 knockouts in Synechocystis demonstrated an enhanced susceptibility to photodamage, which is thought to arise from compromised PSII reaction centers produced by an impaired assembly pathway (Jackson et al. 2014). PSII photoinhibition and repair is also thought to be one strategy to protect PSI from irreversible damage (Tikkanen et al. 2014). E. huxleyi is well known for its tolerance to high light and has been shown to resist photoinhibition at light intensities up to $1500 \mu \mathrm{mol}$ photons $\mathrm{m}^{-2} \mathrm{~s}^{-1}$ (Nanninga \& Tyrrell 1996). Surprisingly, a recent proteomic study found that such adaptation to high light did not involve enhanced production of FtsH or HCF136 (McKew et al. 2013b), even though net D1 repair rates increased in cultures exposed to high photon flux densities (McKew et al. 2013a). While these data suggest that other factors may be important to determine the rate of D1 repair in E. huxleyi, they also underscore the importance of FtsH and HCF136 in maintaining PSII integrity and function under a variety of environmental conditions. 
In contrast to the PSII repair genes, psbA transcript levels did not change significantly in our study during early infection or even as late as $19 \mathrm{~h}$ p.i. D1 production is regulated not by transcription but by translation initiation or elongation in protists and plants, respectively, and $p s b A$ appears to be constitutively expressed in most photosynthetic organisms (Mulo et al. 2012). Not only that, but psbA mRNA can have a very long half-life (>40 h) (Kim et al. 1993b), so together, these factors may explain the difference in transcriptional patterns observed here. Investigating changes in D1 protein concentrations in infected $E$. huxleyi would be an appropriate future approach but was unfortunately beyond the scope of this study.

The precise implications for reduced sod2 transcripts and potentially diminished levels of SOD during infection are still unclear. SOD plays an important role in the quenching of ROS at PSII and PSI (Song et al. 2006, Krieger-Liszkay et al. 2011). Therefore, lower sod2 expression coupled with lower PSII repair gene expression in infected E. huxleyi may result in enhanced $\mathrm{O}_{2}{ }^{--}$production, which could accelerate PSII damage, unless other mechanisms compensate for the SOD deficiency. Likewise, APX is an important enzyme to detoxify $\mathrm{H}_{2} \mathrm{O}_{2}$ in the chloroplast (Mittler 2002, Asada 2006). The significant increases in NSV after $4 \mathrm{~h}$ p.i. coupled with declining sod2 and apx expression suggest a shift from enzymatic quenching of ROS to heat dissipation during infection.

It is challenging to decipher which components of NPQ contribute to the increased heat dissipation in the infected cultures, evident as an increase in NSV (Fig. 2B). It seems likely that both infection-mediated photoinhibition and photodamage, the qI component of NPQ, and the $\mathrm{qE}$ photoprotective mechanism combine to reduce excess excitation energy and ROS production. E. huxleyi has been shown to adjust its capacity for $\mathrm{qE}$ when acclimated to different light regimes and possibly as a result of viral infection. High light adapted E. huxleyi accumulate excess carotenoid pigments such as the xanthophyll diadinoxanthin and $\beta$-carotene to enhance NPQ and prevent over-oxidation of $\mathrm{P}_{680}{ }^{+}$(McKew et al. 2013a). Similarly, an increase in the de-epoxidation state of xanthophylls and a decline in $\beta$-carotene pools following a reduction in photochemical efficiency have been observed during late stages of EhV-86 infection (Llewellyn et al. 2007). That study observed that $\beta$ carotene, an important carotenoid and biosynthetic precursor to xanthophylls, declined starting at $48 \mathrm{~h}$ p.i. It also reported increases in the diadinoxanthin:diatoxanthin ratio consistent with a heightened qE-based NPQ response. Other studies ob- served an increase in chl a oxidation during late infection (Gledhill et al. 2012, Bale et al. 2013) consistent with impaired photosynthesis and hypothesized that ${ }^{1} \mathrm{O}_{2}$ or $\mathrm{O}_{2}$ generated at $\mathrm{P}_{680}{ }^{+}$may be responsible for the chl a oxidation. While the infection dynamics we observed differed significantly from these studies, together they hint at early virus-induced photophysiological changes, beginning with a reduction in PSII repair and assembly followed by a reduction in enzymatic ROS scavenging by SOD and APX and an increase in NPQ that may involve the xanthophyll cycle.

E. huxleyi possess other ROS scavenging pathways that we have not investigated here. For example, in photosynthetic organisms, $\mathrm{H}_{2} \mathrm{O}_{2}$ may be reduced to water or oxygen by several enzymatic pathways, including glutathione peroxidases (Mittler 2002), which have been putatively identified in the E. huxleyi genome (Read et al. 2013). Early evidence of suppression of glutathione peroxidase activity during EhV infection was presented by Gledhill et al. (2012). In the glutathione peroxidase cycle, 1 molecule of $\mathrm{H}_{2} \mathrm{O}_{2}$ is reduced to water, while 2 molecules of glutathione (GSH) are oxidized by glutathione peroxidase (Mittler 2002). Intracellular GSH increased during late stages of EhV-86 infection (Gledhill et al. 2012), suggesting that the glutathione peroxidase cycle is disrupted and providing evidence for another potential mechanism for increased intracellular ROS. Altogether, previous studies and our work here point toward virus-induced repression of multiple ROS scavenging pathways in infected E. huxleyi.

One complicating factor in trying to unify multiple studies is the difficulty in producing a synchronous infection of EhV. Determining the magnitude of changes in gene expression and physiology is difficult without knowing the proportion of infected cells within a culture or natural assemblage and the precise stage of infection of a cell at any given time. While over $80 \%$ of the cells in our study appeared visibly infected by as early as $9 \mathrm{~h}$ p.i. (prior to measurable virus production), we did not achieve a completely synchronous infection (Fig. 1). Perceived differences in expression over time may reflect more cells becoming infected rather than increasing suppression of previously infected cells. Along similar lines, transcripts in infected cultures may derive solely from the uninfected portion of the population, making expression appear down-regulated when it might actually have been fully suppressed in infected cells.

The ultimate reason for the relatively lower transcript copy number for PSII repair/assembly and 
antioxidant genes remains unclear. One possibility is that these lower gene expression levels are a consequence of a larger, systemic shutdown of host gene transcription during virus infection. For example, Paramecium bursaria Chlorella virus-1 (PBCV-1) infection results in heightened chlorophyll fluorescence quenching and rapid declines in PSII efficiency (Seaton et al. 1995). Seaton and colleagues hypothesized that this swift collapse of the host photosynthetic apparatus derived from viral interruption of repair and maintenance processes as transcription of host genes was arrested. Our gene expression and photophysiological data support the hypothesis that this also applies to the E. huxleyicoccolithovirus system. Indeed, there are other parallels between PBCV-1 and EhV-86 infection, including an increase in thermal dissipation of photons absorbed by PSII, achieved through NPQ reactions, after efficiency reductions are observed (Seaton et al. 1995). If an infected host can no longer produce PSII repair and antioxidant enzymes, then options to dissipate excess energy may be limited to thermal dissipation such as NPQ and related mechanisms.

In conclusion, we observed early and rapid reduced capacity in E. huxleyi CCMP374 PSII repair and maintenance gene transcription following EhV86 infection, which was followed by relatively low superoxide dismutase and ascorbate peroxidase expression. Reductions in $F_{\mathrm{v}} / F_{\mathrm{m}}$ were observed after down-regulation of these genes, suggesting that PSII inefficiencies derived from inefficient repair and maintenance and possibly a dearth of enzymatic antioxidants. Levels of $p s b A$ transcripts were the exception, as they remained unchanged until late in the infection, indicating that they did not directly contribute to the observed decline in $F_{\mathrm{v}} / F_{\mathrm{m}}$. NPQ increased as $F_{\mathrm{v}} / F_{\mathrm{m}}$ and antioxidant transcription declined, suggesting a mechanism by which excess energy resulting from inactivated PSII may be dissipated. By coupling high temporal resolution measurements of PSII efficiency and dPCR measurements of gene expression, we have taken a first step in pinpointing the timing of the virally mediated photophysiological decline and presented some possible underpinning molecular mechanisms. Characterizing the molecular and physiological response at this level of detail will help to define the nature of the interactions between phytoplankton hosts and the virus types that infect them. Given the difficulty in synchronizing infection and in accurately quantifying the physiological status of infected cells even in culture, this system would benefit from future work aimed at the single cell level.
Acknowledgements. Carlton Rauschenberg provided sampling assistance during the experiment. David Chappell from RainDance Technologies provided optimization support for the dPCR and valuable feedback on the manuscript. This research was funded by the Gordon and Betty Moore Foundation through Grant GBMF3397 to W.H.W., S.A.A., D.M.F., and J.M.M.

\section{LITERATURE CITED}

Abreu IA, Cabelli DE (2010) Superoxide dismutases-a review of the metal-associated mechanistic variations. Biochim Biophys Acta 1804:263-274

- Adir N, Zer H, Shochat S, Ohad I (2003) Photoinhibition - a historical perspective. Photosynth Res 76:343-370

> Asada K (2006) Production and scavenging of reactive oxygen species in chloroplasts and their functions. Plant Physiol 141:391-396

> Bale NJ, Airs RL, Kimmance SA, Llewellyn CA (2013) Transformation of chlorophyll a during viral infection of Emiliania huxleyi. Aquat Microb Ecol 69:205-210

> Bidle KD, Vardi A (2011) A chemical arms race at sea mediates algal host-virus interactions. Curr Opin Microbiol 14:449-457

Bidle KD, Haramaty L, Barcelos ERJ, Falkowski P (2007) Viral activation and recruitment of metacaspases in the unicellular coccolithophore, Emiliania huxleyi. Proc Natl Acad Sci USA 104:6049-6054

> Bratbak G, Egge JK, Heldal M (1993) Viral mortality of the marine alga Emiliania huxleyi (Haptophyceae) and termination of algal blooms. Mar Ecol Prog Ser 93:39-48

> Brown CM, Campbell DA, Lawrence JE (2007) Resource dynamics during infection of Micromonas pusilla by virus MpV-Sp1. Environ Microbiol 9:2720-2727

Brussaard CPD, Payet JP, Winter C, Weinbauer MG (2010) Quantification of aquatic viruses by flow cytometry. In: Wilhelm SW, Weinbauer MG, Suttle CA (eds) Manual of aquatic viral ecology. ASLO, Waco, TX, p 102-109

Burkill PH, Archer SD, Robinson C, Nightingale PD, Groom SB, Tarran GA, Zubkov MV (2002) Dimethyl sulphide biogeochemistry within a coccolithophore bloom (DISCO): an overview. Deep-Sea Res II 49:2863-2885

Castberg T, Larsen A, Sandaa RA, Brussaard CPD and others (2001) Microbial population dynamics and diversity during a bloom of the marine coccolithophorid Emiliania huxleyi (Haptophyta). Mar Ecol Prog Ser 221:39-46

> Clokie MR, Shan J, Bailey S, Jia Y, Krisch HM, West S, Mann NH (2006) Transcription of a 'photosynthetic' T4type phage during infection of a marine cyanobacterium. Environ Microbiol 8:827-835

- Dammeyer T, Bagby SC, Sullivan MB, Chisholm SW, Frankenberg-Dinkel N (2008) Efficient phage-mediated pigment biosynthesis in oceanic cyanobacteria. Curr Biol 18:442-448

> Evans C, Malin G, Mills GP, Wilson WH (2006) Viral infection of Emiliania huxleyi (Prymnesiophyceae) leads to elevated production of reactive oxygen species. J Phycol 42:1040-1047

Gledhill M, Devez A, Highfield A, Singleton C, Achterberg EP, Schroeder D (2012) Effect of metals on the lytic cycle of the coccolithovirus, EhV86. Front Microbiol 3:155

Guillard RRL, Ryther JH (1962) Studies of marine planktonic diatoms. I. Cyclotella nana Hustedt, and Detonula confervacea (cleve) Gran. Can J Microbiol 8:229-239 
Highfield A, Evans C, Walne A, Miller PI, Schroeder DC (2014) How many coccolithovirus genotypes does it take to terminate an Emiliania huxleyi bloom? Virology 466-467:138-145

> Jackson SA, Hervey JR, Dale AJ, Eaton-Rye JJ (2014) Removal of both Ycf48 and Psb27 in Synechocystis sp. PCC 6803 disrupts photosystem II assembly and alters $\mathrm{Q}_{\mathrm{A}}^{-}$oxidation in the mature complex. FEBS Lett 588: 3751-3760

> Juneau P, Lawrence JE, Suttle CA, Harrison PJ (2003) Effects of viral infection on photosynthetic processes in the bloom-forming alga Heterosigma akashiwo. Aquat Microb Ecol 31:9-17

Kato Y, Miura E, Ido K, Ifuku K, Sakamoto W (2009) The variegated mutants lacking chloroplastic FtsHs are defective in D1 degradation and accumulate reactive oxygen species. Plant Physiol 151:1790-1801

- Kegel JU, Blaxter M, Allen MJ, Metfies K, Wilson WH, Valentin K (2010) Transcriptional host-virus interaction of Emiliania huxleyi (Haptophyceae) and EhV-86 deduced from combined analysis of expressed sequence tags and microarrays. Eur J Phycol 45:1-12

$>$ Kim JH, Nemson JA, Melis A (1993a) Photosystem II reaction center damage and repair in Dunaliella salina (green alga) (analysis under physiological and irradiance-stress conditions). Plant Physiol 103:181-189

> Kim M, Christopher DA, Mullet JE (1993b) Direct evidence for selective modulation of psbA, rpoA, rbcL and $16 \mathrm{~S}$ RNA stability during barley chloroplast development. Plant Mol Biol 22:447-463

Kimmance SA, Allen MJ, Pagarete A, Martínez Martínez J, Wilson WH (2014) Reduction in photosystem II efficiency during a virus-controlled Emiliania huxleyi bloom. Mar Ecol Prog Ser 495:65-76

Kitayama K, Kitayama M, Osafune T, Togasaki RK (1999) Subcellular localization of iron and manganese superoxide dismutase in Chlamidomonas reinhardtii (Chlorophyceae). J Phycol 35:136-142

Komenda J, Nickelsen J, Tichy M, Prasil O, Eichacker LA, Nixon PJ (2008) The cyanobacterial homologue of HCF136/YCF48 is a component of an early photosystem II assembly complex and is important for both the efficient assembly and repair of photosystem II in Synechocystis sp. PCC 6803. J Biol Chem 283:22390-22399

Komenda J, Sobotka R, Nixon PJ (2012) Assembling and maintaining the photosystem II complex in chloroplasts and cyanobacteria. Curr Opin Plant Biol 15:245-251

Krieger-Liszkay A, Kós PB, Hideg É (2011) Superoxide anion radicals generated by methylviologen in photosystem I damage photosystem II. Physiol Plant 142:17-25

> Kyle DJ, Ohad I, Arntzen CJ (1984) Membrane protein damage and repair: selective loss of a quinone-protein function in chloroplast membranes. Proc Natl Acad Sci USA 81:4070-4074

- Latifi A, Ruiz M, Zhang CC (2009) Oxidative stress in cyanobacteria. FEMS Microbiol Rev 33:258-278

- Levasseur M, Thompson PA, Harrison PJ (1993) Physiological acclimation of marine phytoplankton to different nitrogen sources. J Phycol 29:587-595

> Li T, Huang X, Zhou R, Liu Y, Li B, Nomura C, Zhao J (2002) Differential expression and localization of $\mathrm{Mn}$ and $\mathrm{Fe}$ superoxide dismutases in the heterocystous cyanobacterium Anabaena sp. strain PCC 7120. J Bacteriol 184: 5096-5103

> Llewellyn CA, Evans C, Airs RL, Cook I, Bale N, Wilson WH
(2007) The response of carotenoids and chlorophylls during virus infection of Emiliania huxleyi (Prymnesiophyceae). J Exp Mar Biol Ecol 344:101-112

> Lohr M, Wilhelm C (1999) Algae displaying the diadinoxanthin cycle also possess the violaxanthin cycle. Proc Natl Acad Sci USA 96:8784-8789

> Mackinder LC, Worthy CA, Biggi G, Hall M and others (2009) A unicellular algal virus, Emiliania huxleyi virus 86, exploits an animal-like infection strategy. J Gen Virol 90:2306-2316

Mann NH, Cook A, Millard A, Bailey S, Clokie M (2003) Marine ecosystems: bacterial photosynthesis genes in a virus. Nature 424:741

- Martínez Martínez J, Schroeder DC, Larsen A, Bratbak G, Wilson WH (2007) Molecular dynamics of Emiliania huxleyi and cooccurring viruses during two separate mesocosm studies. Appl Environ Microbiol 73:554-562

Martínez Martínez J, Poulton NJ, Stepanauskas R, Sieracki ME, Wilson WH (2011) Targeted sorting of single virusinfected cells of the coccolithophore Emiliania huxleyi. PLOS ONE 6:e22520

> McKew BA, Davey P, Finch SJ, Hopkins J and others (2013a) The trade-off between the light-harvesting and photoprotective functions of fucoxanthin-chlorophyll proteins dominates light acclimation in Emiliania huxleyi (clone CCMP 1516). New Phytol 200:74-85

> McKew BA, Lefebvre SC, Achterberg EP, Metodieva G, Raines CA, Metodiev MV, Geider RJ (2013b) Plasticity in the proteome of Emiliania huxleyi CCMP 1516 to extremes of light is highly targeted. New Phytol 200:61-73

Mittler R (2002) Oxidative stress, antioxidants and stress tolerance. Trends Plant Sci 7:405-410

> Mulo P, Sakurai I, Aro EM (2012) Strategies for psbA gene expression in cyanobacteria, green algae and higher plants: from transcription to PSII repair. Biochim Biophys Acta 1817:247-257

Nanninga HJ, Tyrrell T (1996) Importance of light for the formation of algal blooms by Emiliania huxleyi. Mar Ecol Prog Ser 136:195-203

Nath K, Jajoo A, Poudyal RS, Timilsina R and others (2013) Towards a critical understanding of the photosystem II repair mechanism and its regulation during stress conditions. FEBS Lett 587:3372-3381

Nishiyama Y, Allakhverdiev SI, Murata N (2011) Protein synthesis is the primary target of reactive oxygen species in the photoinhibition of photosystem II. Physiol Plant 142:35-46

> Nixon PJ, Barker M, Boehm M, de Vries R, Komenda J (2005) FtsH-mediated repair of the photosystem II complex in response to light stress. J Exp Bot 56:357-363

> Paasche E (2001) A review of the coccolithophorid Emiliania huxleyi (Prymnesiophyceae), with particular reference to growth, coccolith formation, and calcification-photosynthesis interactions. Phycologia 40:503-529

Pilon M, Ravet K, Tapken W (2011) The biogenesis and physiological function of chloroplast superoxide dismutases. Biochim Biophys Acta1807:989-998

Pospíšil P (2009) Production of reactive oxygen species by photosystem II. Biochim Biophys Acta 1787:1151-1160

Read BA, Kegel J, Klute MJ, Kuo A and others (2013) Pan genome of the phytoplankton Emiliania underpins its global distribution. Nature 499:209-213

> Roose JL, Pakrasi HB (2004) Evidence that D1 processing is required for manganese binding and extrinsic protein assembly into photosystem II. J Biol Chem 279:45417-45422 
Rosenwasser S, Mausz MA, Schatz D, Sheyn U and others (2014) Rewiring host lipid metabolism by large viruses determines the fate of Emiliania huxleyi, a bloom-forming alga in the ocean. Plant Cell 26:2689-2707

Satoh K, Yamamoto Y (2007) The carboxyl-terminal processing of precursor D1 protein of the photosystem II reaction center. Photosynth Res 94:203-215

Seaton GGR, Lee K, Rohozinski J (1995) Photosynthetic shutdown in Chlorella NC64A associated with the infection cycle of Paramecium bursaria Chlorella virus-1. Plant Physiol 108:1431-1438

Shestakov SV, Anbudurai PR, Stanbekova GE, Gadzhiev A, Lind LK, Pakrasi HB (1994) Molecular cloning and characterization of the ctpA gene encoding a carboxylterminal processing protease. Analysis of a spontaneous photosystem II-deficient mutant strain of the cyanobacterium Synechocystis sp. PCC 6803. J Biol Chem 269: 19354-19359

Song YG, Liu B, Wang LF, Li MH, Liu Y (2006) Damage to the oxygen-evolving complex by superoxide anion, hydrogen peroxide, and hydroxyl radical in photoinhibition of photosystem II. Photosynth Res 90:67-78

Stransky H, Hager A (1970) The carotenoid pattern and the occurrence of the light induced xanthophyll cycle in various classes of algae. II. Xanthophyceae. Arch Mikrobiol 71:164-190 (in German)

Suttle CA, Chan AM (1993) Marine cyanophages infecting oceanic and coastal strains of Synechococcus: abundance, morphology, cross-infectivity and growth characteristics. Mar Ecol Prog Ser 92:99-109

Suttle CA, Chan AM, Cottrell MT (1990) Infection of phytoplankton by viruses and reduction of primary productivity. Nature 347:467-469

Editorial responsibility: Katherine Richardson, Copenhagen, Denmark
Thompson LR, Zeng Q, Kelly L, Huang KH, Singer AU, Stubbe J, Chisholm SW (2011) Phage auxiliary metabolic genes and the redirection of cyanobacterial host carbon metabolism. Proc Natl Acad Sci USA 108:E757-E764

Tikkanen M, Mekala NR, Aro EM (2014) Photosystem II photoinhibition-repair cycle protects photosystem I from irreversible damage. Biochim Biophys Acta 1837: 210-215

- Van Etten JL, Burbank DE, Xia Y, Meints RH (1983) Growth cycle of a virus, PBCV-1, that infects Chlorella-like algae. Virology 126:117-125

- Vardi A, Van Mooy BA, Fredricks HF, Popendorf KJ, Ossolinski JE, Haramaty L, Bidle KD (2009) Viral glycosphingolipids induce lytic infection and cell death in marine phytoplankton. Science 326:861-865

- Vardi A, Haramaty L, Van Mooy BA, Fredricks HF, Kimmance SA, Larsen A, Bidle KD (2012) Host-virus dynamics and subcellular controls of cell fate in a natural coccolithophore population. Proc Natl Acad Sci USA 109: 19327-19332

Wagner R, Aigner H, Funk C (2012) FtsH proteases located in the plant chloroplast. Physiol Plant 145:203-214

Wilson WH, Tarran G, Zubkov MV (2002a) Virus dynamics in a coccolithophore-dominated bloom in the North Sea. Deep-Sea Res II 49:2951-2963

> Wilson WH, Tarran GA, Schroeder D, Cox M, Oke J, Malin $\mathrm{G}(2002 \mathrm{~b})$ Isolation of viruses responsible for the demise of an Emiliania huxleyi bloom in the English Channel. J Mar Biol Assoc UK 82:369-377

> Wolfe-Simon F, Starovoytov V, Reinfelder JR, Schofield O, Falkowski PG (2006) Localization and role of manganese superoxide dismutase in a marine diatom. Plant Physiol 142:1701-1709

Submitted: February 17, 2016; Accepted: June 15, 2016 Proofs received from author(s): August 2, 2016 